\title{
A 38-year study on Trichinella spp. in wild boar (Sus scrofa) of Latvia shows a stable incidence with an increased parasite biomass in the last decade
}

Muza Kirjušina ${ }^{1 *}$, Gunita Deksne², Gianluca Marucci ${ }^{3}$, Eduards Bakasejevs ${ }^{1}$, Inese Jahundoviča ${ }^{1}$, Anžela Daukšte ${ }^{1}$, Aleksandra Zdankovska' ${ }^{1}$ Zanda Bērziña ${ }^{2}$, Zanda Esìte ${ }^{2}$, Antonino Bella ${ }^{4}$, Fabio Galati ${ }^{5}$, Angelika Krūmiña ${ }^{6}$ and Edoardo Pozio ${ }^{3}$

\begin{abstract}
Background: Trichinella spp. are zoonotic parasites transmitted to humans by the consumption of raw or insufficiently cooked meat of different animal species. The most common source of infection for humans is meat from pigs and wild boar (Sus scrofa). The aim of the present work was to evaluate the incidence of Trichinella spp. infections in wild boar hunted in Latvia over a 38 year interval (1976 to 2013).

Methods: A total 120,609 wild boars were individually tested for Trichinella spp. by trichinoscopy and, in case of negativity, by artificial digestion of $25 \mathrm{~g}$ muscles, in the 1976-2005 period, and by artificial digestion of 25-50 $\mathrm{g}$ muscles in the 2006-2013 period. Trichinella spp. larvae were identified the species level by multiplex PCR.

Results: In the study period, the overall prevalence of infected wild boar was $2.5 \%$. Trichinella britovi was the predominant (90\%) species. The incidence of Trichinella spp. infection in wild boar exhibited two different trends. From 1976 to 1987, the incidence of infected/hunted wild boar increased from $0.23 \%$ to $2.56 \%$, then it decreased to 0.19 in 1994. Thereafter, the incidence fluctuated between $0.05 \%$ and $0.37 \%$. A statistically significant $(P<0.05)$ correlation ( $r=0.54 ; p=0.0199)$ was found between the trend of Trichinella spp. incidence in hunted wild boar and the number of snow cover days from 1976 to 1993. From 1997 to 2013, the estimated wild boar population of Latvia increased by 4.9 times and the hunting bag by 9.7 times, with a stable incidence of Trichinella spp. in the population. It follows that the biomass of Trichinella spp. larvae and of T. britovi, in particular, increased.
\end{abstract}

Conclusions: The incidence trends of Trichinella spp. in wild boar could be related to the role played by the snow in reducing the thermal shock and muscle putrefaction which increases the survival of the larvae in muscle tissues of carrion in the 1976-1993 period; and, in the 1997-2013 period, to the increased biomass of Trichinella spp. due to the increased carnivore populations, which are the main reservoirs of these parasites.

Keywords: Trichinella britovi, Latvia, Wild boar, Sus scrofa, Incidence, Epidemiology, Biomass, Snow cover, Carnivore

\footnotetext{
* Correspondence: muza.kirjusina@du.lv

'Daugavpils University, Institute of Life Sciences and Technology, Daugavpils, Latvia

Full list of author information is available at the end of the article
} 


\section{Background}

Nematodes of the genus Trichinella are cosmopolitan parasites of carnivorous and omnivorous animals, which can be transmitted to humans by ingestion of raw or semi-raw meat and meat products of different animal origin [1]. The main source of infection for humans is meat from domestic pigs and wild boar (Sus scrofa) [2].

In Latvia, Trichinella spp. infections have been documented in wolves, wild boar and humans since 1960 [3]. From 1955 to 1985, trichinellosis was documented in 152 people who had acquired the infection for the consumption of meat, mostly from wild boar [4]. From 1986 to 2000, 150 cases of human trichinellosis due to the consumption of smoked or undercooked pork (72\%), wild boar meat (23\%), and unknown sources (5\%), were gathered from [5]. Since 1992, human trichinellosis increased from 0.1-0.2 (1982-1991) to 3.75 (2000) cases per 100,000 inhabitants [6]. Then in the period 20002009, the average incidence of trichinellosis was 1.1 per 100,000 inhabitants of Latvia [2]. In the last fifteen years, there has been a marked reduction of human trichinellosis caused by the consumption of pork from domestic pigs in most countries of the European Union. In contrast, the number of infections caused by the consumption of meat from hunted wild boar has remained stable [2]. Among carnivore mammals of Latvia, Trichinella spp. has been detected in the lynx (Lynx lynx), red fox (Vulpes vulpes), raccoon dog (Nyctereutes procyonoides), wolf (Canis lupus), and pine marten (Martes martes) [7-10].

The aims of the present work were to evaluate by a retrospective analysis of longitudinal data, the relationship between the Trichinella spp. incidence in Latvian wild boar and its population growth during the past 38 years, to explore the cause(s), which could have affected the Trichinella spp. incidence in the wild boar population, and to identify the Trichinella species circulating in Latvian wildlife.

\section{Methods}

\section{Source of information}

The number of hunted wild boar tested for Trichinella spp. infection and the number of positive wild boar per district per year, were collected from the annual reports of the National Veterinary Laboratory for the period 1976-1992, from the annual reports of the Veterinary Medicine Diagnostic Centre for the period 1992-2006, and from the annual reports of the National Diagnostic Centre and of the Institute of Food Safety, Animal Health and Environment BIOR, for the period 20062013. Wild boars were collected from all the 26 districts (according to the previous administrative division) of Latvia throughout the year. Data on the estimated wild boar population on April $1^{\text {st }}$ of each year from 1976 to
1990, was gathered from [11]. For the period 1991-2013, this information was downloaded from [12].

Data on the estimated raccoon dog and red fox populations were from [11] and from the State Forest Service (Jānis Ozoliņš, personal communication) for 2010. From 2005 to 2011, carnivore mammals (lynxes, raccoon dogs, red foxes, wolves, martens, domestic dogs, and domestic cats) hunted or killed by cars in Latvia were also screened to detect Trichinella spp. infection and to identify the etiological agents.

\section{Detection of Trichinella infection}

From 1968 to 2005 according to the Latvian Normative act Nr. 5-I0-960 of Latvian SSR Ministry of Agriculture of 9 October 1968, hunters delivered to veterinary services on a voluntary basis no less than $100 \mathrm{~g}$ of diaphragm muscle and $50 \mathrm{~g}$ of tongue muscle from hunted wild boar. Trichinella spp. larvae were searched in 28 small pieces about the size of a grain of rice from the diaphragm samples, by trichinoscopy. When trichinoscopy was negative, $25 \mathrm{~g}$ of muscle samples were individually digested by artificial gastric juice [13]. Briefly, $25 \mathrm{~g}$ from diaphragm and/or tongue muscles of each animal were cut into small pieces by scissors. Chopped meat was then placed on a bee sieve of $15 \mathrm{~cm}$, which was placed in turn on a funnel containing the digestion fluid $(1000 \mathrm{ml}$ of warm water, $5 \mathrm{~g}$ of pepsin, $7 \mathrm{ml}$ of $\mathrm{HCl}$ ) covering the meat. The meat was incubated at $39^{\circ} \mathrm{C}$ for $18 \mathrm{~h}$. Then $5 \mathrm{ml}$ of the digestion fluid was run off from the bottom of the funnel in a conical tube. After $30 \mathrm{~min}$ sedimentation, $3 \mathrm{ml}$ of supernatant were discharged and the remaining $2 \mathrm{ml}$ were poured out in a $6 \mathrm{~cm}$ Petri dish. Larvae were searched under a stereomicroscope at $40 \times$ magnifications. The laboratory personnel were regularly trained on trichinoscopy and digestion methods with frequent observations of positive samples. When a positive wild boar was detected, the carcass was burned down in the presence of a veterinary inspector. From 1976 to 2005, the larval burden per gram of muscle was not evaluated and larvae were not collected for their identification at the species level.

From 2006 to 2013, muscle samples from wild boar $(25-50 \mathrm{~g})$ and carnivores $(25 \mathrm{~g})$ were individually tested by the magnetic stirrer method according to the Commission Regulation 2075/2005 (European Commission, 2005) [14]. The larval burden per gram of muscle was not evaluated but larvae were collected, washed in PBS, and then stored in 70\%-96\% ethyl alcohol for their identification at the species level by a molecular test. Information on Trichinella spp. isolates is available at the website of the International Trichinella Reference Centre [15]. 


\section{Molecular identification of Trichinella spp. larvae}

From 2005 to 2013, at least five single Trichinella spp. larvae isolated by artificial digestion from each positive animal, were identified at the species level by multiplex PCR analysis according to previously published protocols $[16,17]$.

\section{Potential factors influencing the Trichinella spp. prevalence in wild boar}

The following factors were examined to evaluate their potential influence on the Trichinella spp. incidence in wild boar of Latvia in the period 1976-2013: 1) the number of Trichinella spp. infecting domestic pigs per year (Annual reports from 1976 to 1992 of the National Veterinary Laboratory; Annual reports from 1992 to 2006 of the Veterinary Medicine Diagnostic Centre; Annual reports from 2006 to 2011 of the National Diagnostic Centre and of the Institute of Food Safety, Animal Health and Environment BIOR), assuming the Trichinella spp. transmission from the domestic to the sylvatic cycle; 2) the estimated carnivore populations (red foxes and raccoon dogs) per year, since their carcasses left by hunters on the ground, can be the source of Trichinella spp. infections for wild boar; 3) the number of hunted wild boar per year for the reason cited in point 2; 4) the estimated wild boar population per year, since an increased population can result in a feed shortage favouring scavenging behaviour on carrions; 5) the air temperature and precipitation per year $[18,19]$; and 6 ) the number of snow cover days gathered from [20] for the period 1976-2004, and from the website (ftp://ftp. ncdc.noaa.gov/pub/data/gsod) for the period 2005-2013.

\section{Statistical analysis}

The proportion of infected wild boar was evaluated by the Chi-square for trend test. The prevalence of Trichinella spp. was calculated by dividing the number of infected wild boar by the number of hunted wild boar $x$ 100. The Pearson's Correlation Coefficient was used to compare the number of days with snow cover and the rate Trichinella sp. infected/hunted wild boar. $\mathrm{P}<0.05$ was considered significant. The statistical analysis was performed using the STATA 11.2 software.

\section{Results}

In the 38-year period (1976-2013), the estimated average number of wild boar in Latvia was 32,244 heads (range 13,775-74,107) per year (Table 1). The estimated wild boar population size fluctuated in the study period reaching a peak of 33,039 heads in 1992 and a new peak of 74,107 heads in 2013 (Figure 1). The number of hunted heads followed a similar fluctuation (average 15,496; range 3,962-38,723) and was proportional to the estimated wild boar population size (average 48\%; range
Table 1 Estimated, hunted, tested and Trichinella spp. positive wild boar (Sus scrofa) in Latvia

\begin{tabular}{lll}
\hline & Average per year (range) & $\%$ \\
\hline Estimated wild boar population & $32,244(13,775-74,107)$ & \\
Hunted wild boar & $15,496(3,962-38,723)$ & $48^{\mathrm{a}}$ \\
Wild boar tested for Trichinella spp. & $3,174(238-10,138)$ & $20^{\mathrm{b}}$ \\
Wild boar positive for Trichinella spp. & $80(6-369)$ & $2.5^{\mathrm{c}}$ \\
\hline
\end{tabular}

Data have been collected from 1976 to 2013.

a on estimated wild boar population.

bon hunted wild boar.

con tested wild boar.

$22.5 \%-72.5 \%$ ) (Figure 1). From 1997 to 2013, the estimated wild boar population increased by 4.9 times and the hunting bag increased by 9.7 times. An average of $20 \%$ (range $0.54 \%-60.9 \%$ ) of the hunted wild boar were tested for Trichinella spp. and an overall prevalence of $2.5 \%$ was detected in the study period (Table 1 ). The number of tested wild boar and the number of Trichinella spp. positive animals varied among the years (Table 1, Figure 2). From 1976 to 1987, the incidence of infected/hunted wild boar increased from $0.23 \%$ to $2.56 \%$, then it decreased to 0.19 in 1994 . Thereafter, the incidence fluctuated between $0.05 \%$ and $0.37 \%$ (Figure 3).

A statistically significant correlation $(\mathrm{r}=0.54 ; \mathrm{p}=$ 0.0199) was found between the trend of Trichinella spp. incidence in wild boar and the number of snow cover days from 1976 to 1993 (Figure 3). In contrast, from 1994 to 2013 , no correlation $(r=0.08 ; p=0.7628)$ was observed between these two variables.

From 1990 to 2010, the estimated population size of raccoon dogs and red foxes increased by $288 \%$ and $317 \%$, respectively (Figure 4). A correlation was detected between the increased carnivore populations and increased Trichinella spp. biomass in the wild boar population. No relationship was observed between the other investigated variables and the trend of Trichinella spp. incidence in the wild boar population (data not shown).

No correlation was detected between the incidence of Trichinella spp. infection in wild boar and their geographical origin, based on the 26 Latvian districts nor on the four main Latvian regions (Kurzeme, Latgale, Vidzeme and Zemgale) (data not shown). The overall prevalence for the 38 year period ranged from $0.8 \%$ in the Rezekne district up to $10.1 \%$ in the Preili district with the highest prevalence in the centrum and southeastern districts of Latvia (Figure 5).

Trichinella britovi was recovered from 90\% of the Trichinella spp. isolates from wild boar hunted in 15 districts (Figure 5). Trichinella nativa was isolated from three (5.8\%) wild boars killed in two districts; $T$. spiralis was detected in one (1.9\%) wild boar and a 


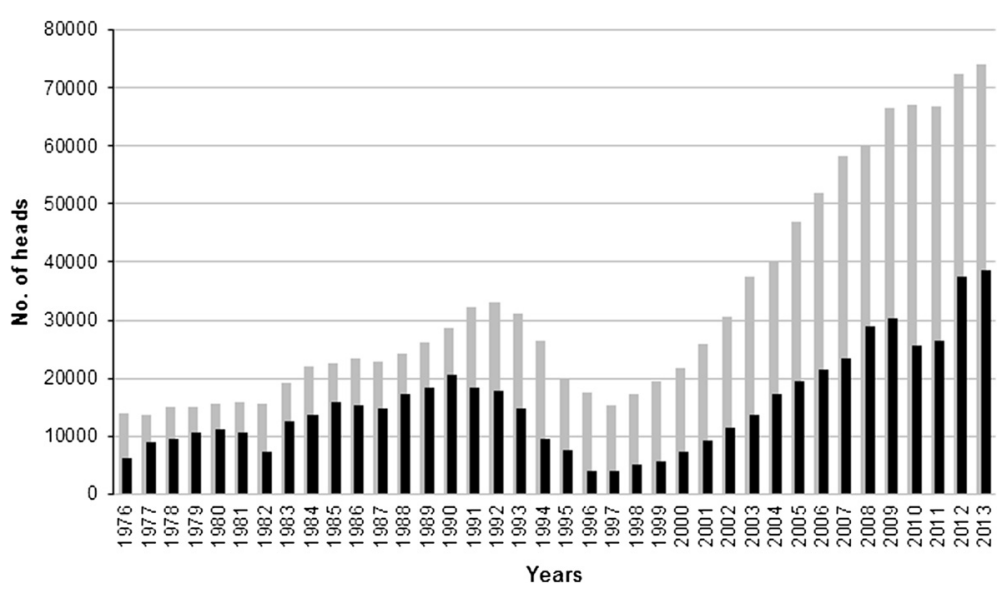

Figure 1 Estimated and hunted wild boar heads in Latvia from 1976 to 2013. Number of estimated heads, grey bar; number of hunted heads, black bar.

mixed $T$. britovi/T. nativa infection in another wild boar (Figure 5).

Overall, from 2005 to 2011, Trichinella spp. larvae were isolated from 179 carnivores. Larvae were identified as T. britovi (96\%), T. nativa (2.8\%) and T. britovi/T. nativa mixed infections (1.1\%). Trichinella britovi was detected in 50 foxes, 43 lynxes, 43 raccoon dogs, 33 wolves, 1 marten, 1 domestic dog and 1 domestic cat; $T$. nativa in 3 wolves and 2 foxes; and mixed T. britovi/T. nativa infections in 1 wolf and 1 fox.

\section{Discussion}

We present valuable data here on the long term (38 years) trends in the incidence of Trichinella spp. in the hunted wild boar population of Latvia. They reveal an increase from $0.23 \%$ to $2.56 \%$ in the period $1976-$ 1987, a decrease up to $0.19 \%$ in 1994, and then a fluctuation from $0.05 \%$ to $0.37 \%$ in the following years
(Figure 3). This trend was not linked to the observed 4.9 fold growth of the host population in the country, with an average number of 1.14 heads per square kilometre in 2013.

A correlation $(\mathrm{r}=0.54 ; \mathrm{p}=0.0199)$ between the incidence trend of Trichinella spp. in wild boar and the number of snow cover day trend during the period 1976-1993 has been observed in the present study (Figure 3). The higher the number of snow cover days, the higher the Trichinella spp. incidence in wild boar and vice versa. This suggests that snowfall favours the survival of Trichinella spp. larvae in decaying host muscles by preventing sudden changes of the carrion temperature (e.g., the action of the wind), and by maintaining a constant humidity. This correlation stresses the importance of the time spent by the larvae in the decaying muscle tissues when they are no longer protected by the host homeothermy. The muscle larvae

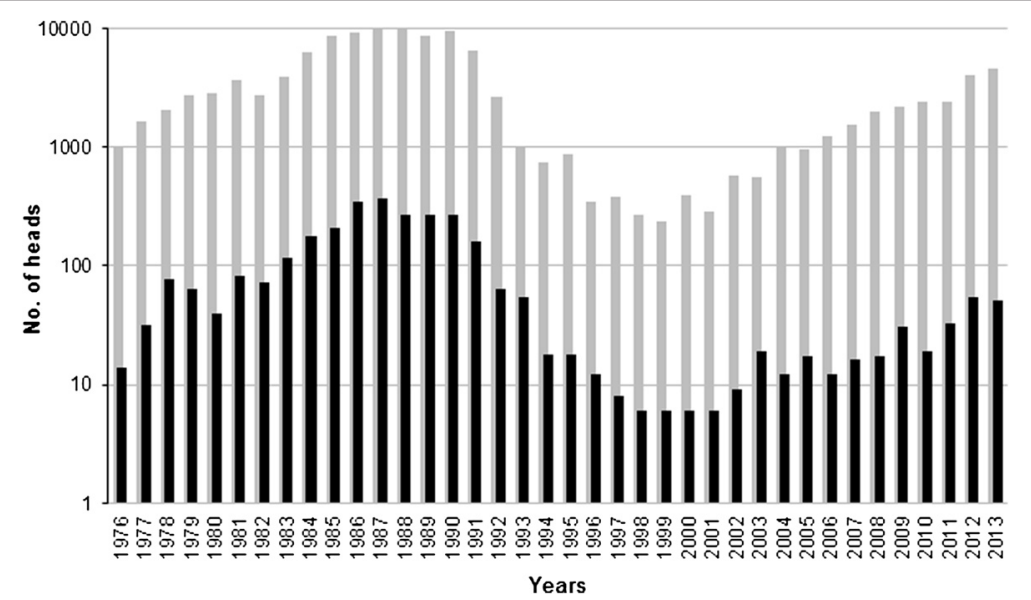

Figure 2 Tested wild boar and Trichinella spp. positive wild boar in Latvia from 1976 to 2013. Number of animals tested for Trichinella spp., grey bar; number of Trichinella spp. positive animals, black bar. Logarithmic scale. 


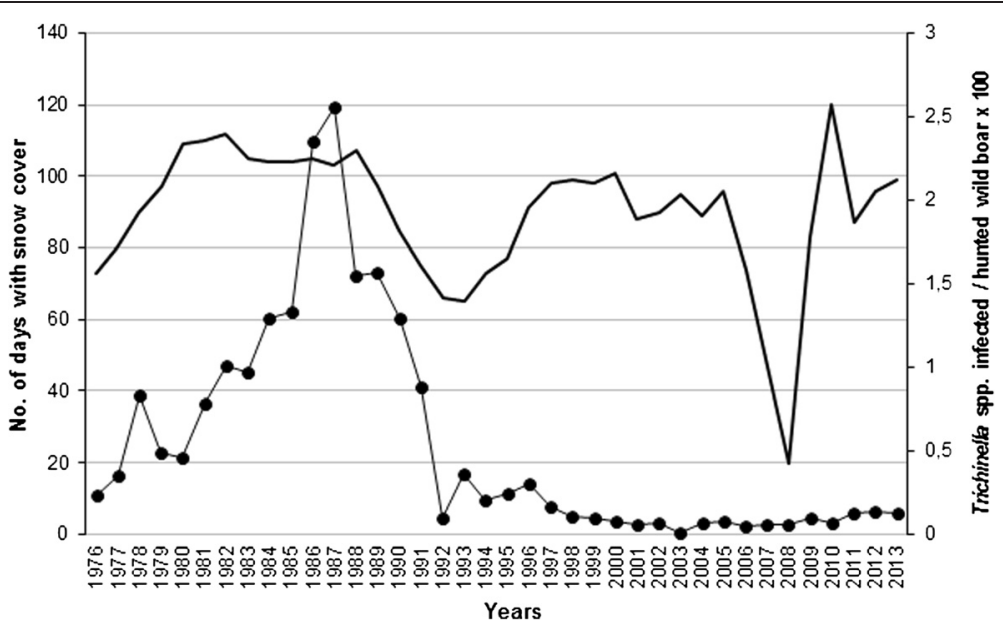

Figure 3 Prevalence of Trichinella spp. in hunted wild boar and snow cover days in Latvia. Number of snow cover days from 1976 to 2013 , solid line; Trichinella spp. infected/hunted wild boar $\times 100$, line with black circles.

have an anaerobic metabolism which supports their survival in decaying muscles over long periods of time, even though the striated muscle tissue develops an angiogenesis process around the muscle cell-larva complex [21]. Madsen [22] considered the ecological niche of the host carrion as the environment of the "freeliving" stage, equivalent to the egg stage of most other nematode species. However, in the absence of snow cover, the carcass can be exposed to rapid decrease/increase of temperature, causing freezing and/or thawing of the muscle tissues which kill the larvae, and/or to a fast drying of the muscle tissues also resulting in the death of the larvae. However, further investigations are needed to evaluate the influence of the environment under the snow [23] on the survival of Trichinella spp. larvae in the host carcasses.
Since the Trichinella spp. incidence in the wild boar population of Latvia was quite uniform in the last 12 years (Figure 3), we can assume a significant increase of the parasite biomass in wild boar due to the growth of wild boar and carnivore populations (Figures 1 and 4). In Latvia, this increased parasite biomass is represented for $90 \%$ by T. britovi even if this species is not considered to be well adapted to swine (see below).

Trichinella britovi is largely the predominant Trichinella species circulating in Latvia where, in addition to wild boar, its prevalence in wild carnivores may vary from $21 \%$ to $50 \%$ in the raccoon dog, $17 \%-57 \%$ in the red fox, $69.6 \%$ in the wolf, $40 \%-90 \%$ in the lynx, and $46.1 \%$ in the pine marten [7-10]. Trichinella spiralis has been documented only in six foxes and in four domestic pigs [8], and in one wild boar (present work).

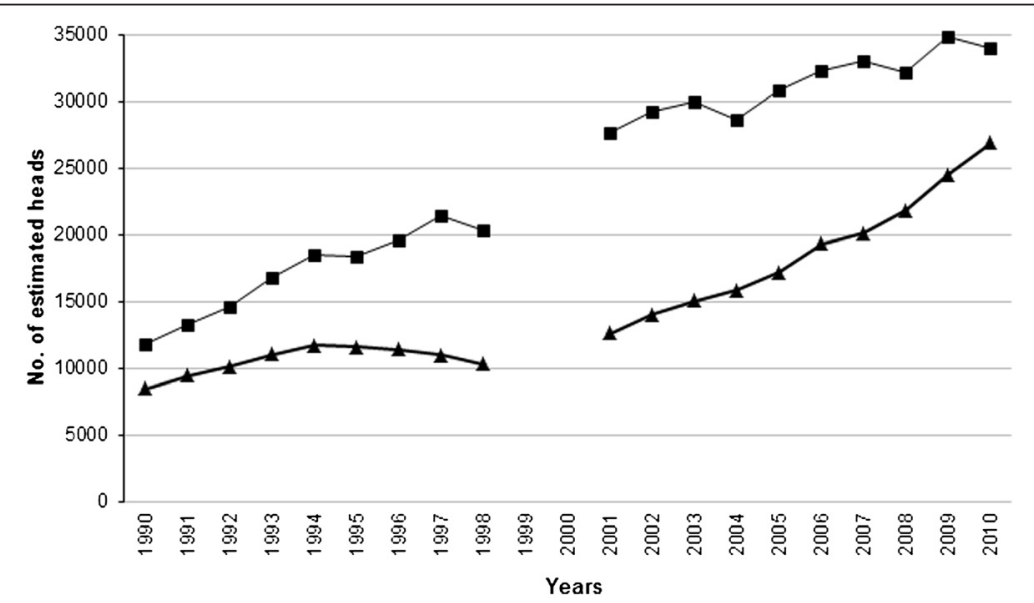

Figure 4 Yearly estimate of red fox and raccoon dog heads in Latvia from 1990 to 2010. Red fox, line with boxes; raccoon dog, line with triangles. No data is available for the years 1999-2000. 


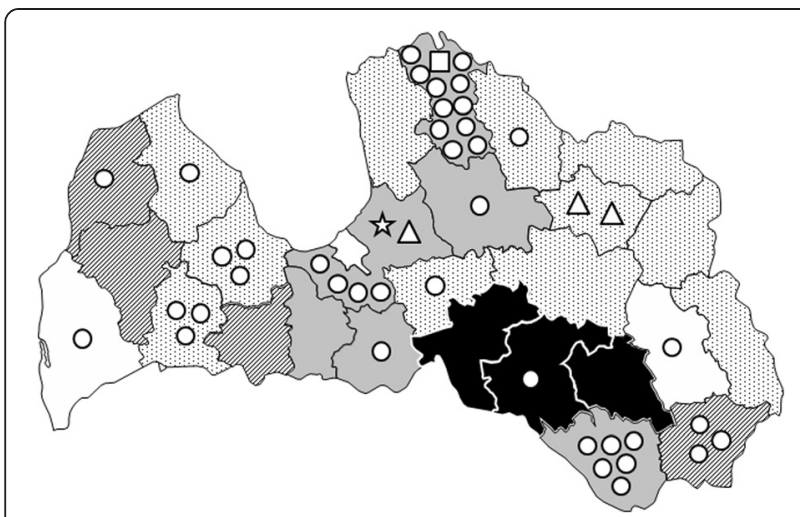

Figure 5 Prevalence of Trichinella spp. in wild boar by Latvian district from 1976 to 2013. White districts, prevalence $\leq 1$; dotted districts, prevalence $>1 \leq 2$; stripped districts, prevalence $>2 \leq 3$; grey districts, prevalence $>3 \leq 4$; black districts, prevalence $>4$. Trichinella spp. isolates from wild boar: Trichinella britovi, circles; Trichinella nativa, triangles; Trichinella spiralis star; mixed T. britovi/T. nativa, box. The district origin of seven T. britovi isolates from wild boar is unknown.

The enteral and parenteral niches of swine are not very favourable to T. britovi; a low worm burden and a short survival time in the muscles is typical [24-26]. Therefore, the overall prevalence of $2.5 \%$ in wild boar during the period $1976-2013$ (1.4\% in the last 12 years) should be considered very high. In European countries, where $T$. britovi is the prevalent species in wildlife, the prevalence of infection in wild boar is 0.3 in Estonia [8], 0.007 in Hungary [27], from 0.002 to 0.017 in Italy [28], 0.51 in Lithuania [8], and 0.06 in the Slovak Republic [29].

Carnivore mammals, canids in particular, are the most important reservoir species of $T$. britovi and $T$. nativa [30,31]. In some European countries, the increase of Trichinella spp. prevalence among wild boar has been related to a concomitant increase of the carnivore populations. In Poland, an increase in the fox population density has been linked with an increase in the prevalence of Trichinella spp. among wild boar [32,33]. In Mecklenburg-Western Pomerania (Germany), the increase of the Trichinella spp. prevalence in wild boar has been associated with the increasing raccoon dog population in the region [34]. In Spain, a decreasing trend of Trichinella spp. in the wild boar population during 1998 to 2009, was associated with an increase in fenced areas, which prevented the circulation of wild carnivores considered the most important reservoir of Trichinella spp. [35]. In Latvia, there has been a concomitant increase of the wild boar and carnivore populations. In 2010, the total estimated number of wild carnivores (lynx, raccoon dog, red fox, wolf, American mink, badger, pine and stone martens, and polecat, about 140,000 heads) [11], the main reservoir hosts for T. britovi [31], was two times higher than the number of estimated wild boar heads (about 67,000, Figure 1). The abundance of carnivores in which the prevalence of Trichinella spp. (96\% $T$. britovi) was extremely high, allows the maintenance of a stable incidence of infection in the wild boar population in spite a 4.9 fold increase and the short survival time of $T$. britovi in this host species.

The increase of the carnivore and wild boar population size may have enhanced the common habit of hunters to leave animal carcasses in the field after skinning, or removing and discarding the entrails, which has been demonstrated to strongly increase the probability of Trichinella spp. transmission among wildlife [22,36-42], and to free-ranging and backyard pigs, particularly if the pig owner is a hunter [42].

In the period 1976-2005, the use of the trichinoscopy test in first instance and then, in the case of a negative result, of the digestion test of single animals, was driven to reduce the number of apparatuses needed to test these animals. The pooled sample digestion test was not used to reduce the need to identify the positive animal/s present in a pool considering an expected prevalence up to $40 \%$ in some districts (data not shown). The use of two, at least in part different, artificial digestion protocols between the 1976-2005 and 2006-2013 periods, does not seem to have influenced the test sensibility, since the incidence detected in the last eight years (2006-2013) was similar to the incidence of the previous eight years (1998-2005).

\section{Conclusions}

In most European countries including Latvia, but also elsewhere, the number of wild boar tested for Trichinella spp. larvae is always a percentage of the hunted animals (Figures 1 and 2). A high percentage of these animals are hunted for own consumption, do not enter into the official market, and escape the veterinary controls, thus causing infections in humans [43]. There is the need to educate hunters on the importance of the systematic examination for Trichinella spp. larvae of game intended for human consumption to prevent human infection. Furthermore, veterinary services should educate hunters not to spread game carcasses or their scraps and offal in the environment, and should organize a system for a proper collection and disposal of these biological samples.

\section{Competing interests}

The authors declare that they have no competing interests.

\section{Authors' contributions}

Conceived and designed the laboratory tests: MK, EP. Performed the experiments: MK, GD, ZB, ZE, EB, AD, AZ, GM, IJ, AK. Analysed the data: AB, FG. Contributed reagents/materials/analysis tools: MK, GD, EP. Drafted the manuscript: MK, EP. All authors read and approved the final manuscript. 


\section{Acknowledgements}

We are very grateful to Jānis Ozolinš who provided us with the estimated number of carnivore populations. This work was in part supported by the European Commission, contracts 2007-2012, project LLII-110 JOINT RT UNIT "Joint Research \& Technology Unit of Universities for entrepreneurs to diversify rural economics" (2010-2012) and by the European Social Fund within the Project "Support for the implementation of doctoral studies at Daugavpils University" Agreement Nr. 2009/0140/1DP/1.1.2.1.2/09/IPIA/VIAA/ 015. The work carried out in Italy was in part supported by the DG SANCO of the European Commission.

\section{Author details}

'Daugavpils University, Institute of Life Sciences and Technology, Daugavpils, Latvia. Institute of Food Safety, Animal Health and Environment "BIOR", Riga, Latvia. ${ }^{3}$ European Union Reference Laboratory for Parasites, Istituto Superiore di Sanità, Rome, Italy. ${ }^{4}$ CNESPS, Istituto Superiore di Sanità, Rome, Italy. ${ }^{5}$ SIDBAE, Istituto Superiore di Sanità, Rome, Italy. ${ }^{6}$ Riga Stradinš̌ University, Riga, Latvia.

\section{Received: 17 October 2014 Accepted: 18 February 2015} Published online: 01 March 2015

\section{References}

1. Gottstein B, Pozio E, Nöckler K. Epidemiology, diagnosis, treatment, and control of trichinellosis. Clin Microbiol Rev. 2009;22:127-45.

2. Murrell KD, Pozio E. Worldwide occurrence and impact of human trichinellosis, 1986-2009. Emerg Infect Dis. 2011;17:2194-202.

3. Viksne AE. Epizootiological and epidemiological problems of trichinellosis in Latvian SSR. Wiad Parazytol. 1970;16:73.

4. Lazdina MA, Nesaule VM. Occurrence of human trichinellosis in the Latvian S.S.R., 1955-1988. In: Valdman EK, editor. Actual trends of parasitology in the Baltic States: XI Scientific Conference on Parasitology in the Baltic States Tallinn: Information Center of the State Agro-Industrial Committee of the Estonian S.S.R. 1989. p. 89 [in Russian].

5. Viksna L, Keiss J, Sondore V, Rozentale B. Trichinellosis in Latvia: how big is the problem? In: Mugurevics A, editor. Animals health food quality. Jelgava: Veterinary medicine papers; 2002. p. 303-6.

6. Keidans P, Kruklite A, Keidane D, Kirjusina M, Lucenko I. Epidemiological studies of human trichinellosis. In: Mugurevics A, editor. Animals health food quality. Jelgava: Veterinary medicine papers; 2002. p. 93-9 [in Latvian]

7. Bagrade G, Vismanis K, Kirjusina M, Ozolins J. Preliminary results on the helminthofauna of the Eurasia lynx (Lynx lynx) in Latvia. Acta Zool Lituanica. 2003;13:3-7

8. Malakauskas A, Paulauskas V, Järvis T, Keidans P, Eddi C, Kapel CM. Molecular epidemiology of Trichinella spp. in three Baltic countries: Lithuania, Latvia, and Estonia. Parasitol Res. 2007;100:687-93.

9. Bakasejevs E, Daukste A, Zolovs M, Zdanovska A. Investigation of Trichinella in wildlife in Latgale region (Latvia). Acta Biol Daugavp. 2012;12:1-5.

10. Bagrade G, Kirjusina M, Vismanis K, Ozolins J. Helminth parasites of the wolf Canis lupus from Latvia. J Helminthol. 2009;83:63-8.

11. Vanags J. Hunting. Knowledge and truth. In: The author's edition. 2010. ISBN 978-9984-39-933-1 [in Latvian].

12. State forest service. https://www.zm.gov.lv/valsts-meza-dienests/statiskaslapas/medibas/valsts-meza-dienests/statiskas-lapas/skaitli-un-fakti? id=766\#jump. Accessed 12 Jan 2015.

13. Berezancev JA. A simple method of muscles investigation for trichinellosis by digestion in artificial gastric juice. Lab Work. 1960;6:7-8 [in Russian].

14. Community E. Regulation (EC) No. 2075/2005 of the European Parliament and of the Council of 5 December 2005 laying down specific rules on official controls for Trichinella in meat. Off J EC L. 2005;338:60-82.

15. International Trichinella Reference Centre. http://www.iss.it/site/Trichinella/ index.asp. Accessed 12 Jan 2015.

16. Pozio E, La Rosa G. PCR-derived methods for the identification of Trichinella parasites from animal and human samples. Methods Mol Biol. 2003;216:299-309.

17. Pozio E, La Rosa G. Trichinella. In: Liu D, editor. Molecular detection of foodborne pathogens. Boca Raton: CRC Press, Taylor \& Francis Group; 2010 p. 851-63.

18. Lizuma L, Klavinšs M, Briede A, Rodinovs V. Long-term changes of air temperature in Latvia. In: Klavinš̌ M, editor. Climate change in Latvia. Riga: LU Akadēmiskais apgāds; 2007. p. 11-20.
19. Briede A, Lizuma L. Long-term variability of precipitation in the territory of Latvia. In: Klavinš̌ M, editor. Climate change in Latvia. Riga: LU Akadēmiskais apgāds; 2007. p. 35-44.

20. Draveniece A, Briede A, Rodinovs V, Klavinš M. Long-term changes of snow cover in Latvia as an indicator of climate variability. In: Klaviņš M, editor.

Climate change in Latvia. Riga: LU Akadēmiskais apgāds; 2007. p. 73-85.

21. Despommier DD. How does Trichinella spiralis make itself at home? Parasitol Today. 1998;14:318-23.

22. Madsen $\mathrm{H}$. The principles of the epidemiology of trichinellosis with a new view on the life cycle. In: Kim CW, editor. Trichinellosis. New York: Intext Educational Publishers; 1974. p. 615-38.

23. Pauli JN, Zuckerberg B, Whiteman JP, Porter W. The subnivium: a deteriorating seasonal refugium. Front Ecol Environ. 2013;11:260-7.

24. Kapel CMO, Gamble HR. Infectivity, persistence, and antibody response to domestic and sylvatic Trichinella spp. in experimentally infected pigs. Int J Parasitol. 2000:30:215-21.

25. Kapel CMO. Sylvatic and domestic Trichinella spp. in wild boars; infectivity, muscle larvae distribution, and antibody response. J Parasitol. 2001;87:309-14.

26. Nöckler K, Serrano FJ, Boireau P, Kapel CM, Pozio E. Experimental studies in pigs on Trichinella detection in different diagnostic matrices. Vet Parasitol. 2005;132:85-90

27. Széll Z, Marucci G, Ludovisi A, Gómez-Morales MA, Sréter T, Pozio E. Spatial distribution of Trichinella britovi, T. spiralis and T. pseudospiralis of domestic pigs and wild boars (Sus scrofa) in Hungary. Vet Parasitol. 2012;183:393-6.

28. Gómez-Morales MA, Ludovisi A, Amati M, Bandino E, Capelli G, Corrias F, et al. Indirect versus direct detection methods of Trichinella spp. infection in wild boar (Sus scrofa). Parasit Vectors. 2014;7:171.

29. Hurníková Z, Dubinský P. Long-term survey on Trichinella prevalence in wildlife of Slovakia. Long-term survey on Trichinella prevalence in wildlife of Slovakia. Vet Parasitol. 2009;159:276-80.

30. Pozio E, Rinaldi L, Marucci G, Musella V, Galati F, Cringoli G, et al. Hosts and habitats of Trichinella spiralis and Trichinella britovi in Europe. Int J Parasitol. 2009;39:71-9.

31. Pozio E, Zarlenga DS. New pieces of the Trichinella puzzle. Int J Parasitol. 2013;43:983-97.

32. Balicka-Ramisz A, Grupiński T, Ramisz A, Pilarczyk B, Laurans L. Prevalence of Trichinella spp. in red foxes and wild boars in the northwestern part of Poland. Dtsch Tierarztl Wochenschr. 2007;114:354-7 [in German].

33. Ramisz A, Grupinski T, Balicka-Ramisz A, Udała J, Luarans Ł. Prevalence of Trichinella sp. in red foxes and wild boars in the Western Pomerania Region. Bull Vet Inst Pulawy. 2011;55:199-201.

34. Pannwitz G, Mayer-Scholl A, Balicka-Ramisz A, Nockler K. Increased prevalence of Trichinella spp., northeastern Germany, 2008. Emerg Infect Dis. 2010;16:936-42.

35. Boadella M, Barasona JA, Pozio E, Montoro V, Vicente J, Gortazar C, et al. Spatio-temporal trends and risk factors for Trichinella species infection in wild boar (Sus scrofa) populations of central Spain: a long-term study. Int J Parasitol. 2012;42:739-45.

36. Cironeanu I. Trichinellosis in domestic and wild animals in Romania. In: Kim CW, editor. Trichinellosis. New York: In text Educational Publishers; 1974. p. 549-55.

37. Batkaev Al, Vakker VG. The role of corsac fox in circulation of trichinelles in the Middle Irtysh territory. In: Proceedings of the $6^{\text {th }}$ Scientific Conference on Trichinellosis, 12-14 May. Kirov, Moscow: Russian Academy of Sciences; 1992. p. 24-6.

38. Worley DE, Seesee FM, Zarlenga DS, Murrell KD. Attempts to eradicate trichinellosis from a wild boar population in a private game park (U.S.A.). In: Campbell CW, Pozio E, Bruschi F, editors. Trichinellosis. Rome: Istituto Superiore di Sanità Press; 1994. p. 611-6.

39. Pérez-Martin J, Serrano FJ, Reina D, Mora JA, Navarrete I. Sylvatic trichinellosis in southwestern Spain. J Wildl Dis. 2000;36:531-4.

40. Pozio E, Casulli A, Bologov W, Marucci G, La Rosa G. Hunting practices increase the prevalence of Trichinella infection in wolves from European Russia. J Parasitol. 2001:87:1498-501.

41. Pozio E, Murrell KD. Systematics and epidemiology of Trichinella. Adv Parasitol. 2006:63:367-439. 
42. Pozio E. Searching for Trichinella: not all pigs are created equal. Trends Parasitol. 2014;30:4-11.

43. Fichi G, Stefanelli S, Pagani A, Luchi S, De Gennaro M, Gómez-Morales MA, et al. Trichinellosis outbreak caused by meat from a wild boar hunted in an Italian region considered to be at negligible risk for Trichinella. Zoonoses Public Health. 2014. [in press].

Submit your next manuscript to BioMed Central and take full advantage of:

- Convenient online submission

- Thorough peer review

- No space constraints or color figure charges

- Immediate publication on acceptance

- Inclusion in PubMed, CAS, Scopus and Google Scholar

- Research which is freely available for redistribution 